The University of Southern Mississippi

The Aquila Digital Community

Faculty Publications

$1-1-2021$

\title{
Preschool Mathematics Performance and Executive Function: Rural-Urban Comparisons across Time
}

\author{
Jacob A. Esplin \\ University of Southern Mississippi, jacob.esplin@usm.edu \\ Ann M. Berghout Austin \\ Utah State University \\ Belinda Blevins-Knabe \\ University of Arkansas at Little Rock \\ Brionne G. Neilson \\ Southern Utah University \\ Robert F. Corwyn \\ University of Arkansas at Little Rock
}

Follow this and additional works at: https://aquila.usm.edu/fac_pubs

Part of the Science and Mathematics Education Commons

\section{Recommended Citation}

Esplin, J., Berghout Austin, A., Blevins-Knabe, B., Neilson, B., Corwyn, R. (2021). Preschool Mathematics Performance and Executive Function: Rural-Urban Comparisons across Time. Journal of Research in Childhood Education, 35(3), 458-476.

Available at: https://aquila.usm.edu/fac_pubs/18993

This Article is brought to you for free and open access by The Aquila Digital Community. It has been accepted for inclusion in Faculty Publications by an authorized administrator of The Aquila Digital Community. For more information, please contact Joshua.Cromwell@usm.edu. 
Preschool mathematics performance and executive function:

Rural-urban comparisons across time

\author{
Jacob Esplin, Ph.D. \\ Southern Mississippi University \\ Ann M. Berghout Austin, Ph.D. \\ Utah State University \\ Belinda Blevins-Knabe, Ph.D. \\ University of Arkansas at Little Rock \\ Brionne Thompson, Ph.D. \\ Southern Utah University \\ Robert C. Corwyn, Ph.D. \\ University of Arkansas at Little Rock
}

We thank the Utah Agricultural Experiment Station and the Utah Office of Childcare for their support of this work.

We are grateful to the parents, providers, and little children who participated so cheerfully in this study. 


\begin{abstract}
This longitudinal study, with urban and rural preschool children, examines the relationship between executive function $(\mathrm{EF})$ and mathematics. A panel of direct and indirect measures of EF were used to determine which EF measures were most predictive and a measure of mathematics assessed both numeracy and geometry skill. One hundred eighteen children, ages 39 to 68 months, and their preschool teachers were included, with assessments given twice, about six months apart. EF measures were compared by the amount of variance in mathematics skill each claimed, including the influence of a child's age, gender, and rural-urban context. Results suggest the child's age determines if a panel of direct EF measures is a better predictor of numeracy and geometry skills than the use of a single EF measure. Different EF measures were more strongly related to numeracy versus geometry at Time 1 and Time 2. Differences unrelated to income were found between rural and urban children on numeracy skill but not geometry skill. These results are particularly important to state and regional early childhood directors who work across urban and rural areas, legislators and policymakers, teachers and parents.
\end{abstract}

Keywords: rural-urban context, geometry skill, numeracy skill, executive function, early childhood mathematics, assessment 


\section{Introduction}

The pre-k connection between numeracy and executive function (EF) is supported in most (e.g., Best, Miller, \& Naglieri, 2011; Fuhs, Nesbitt, Farran, \& Dong, 2014; Mazzocco \& Kover, 2007) but not all studies (e.g., Eden and Potter, 2013). Where linkages are reported, the relationships are often complex (Clements, Sarama, \& Germeroth, 2016). Some report that EF predicts mathematics performance (e.g., Best et al., 2011; Jacob \& Parkinson, 2015), while others report that mathematics skills support the development of EF (e.g., McClelland et al., 2007). Most scholars now believe that the relationship between EF and mathematics is bidirectional, at least during the preschool years (e.g., Fuhs et al., 2014; Schmitt, Geldhof, Purpura, Duncan, \& McClelland, 2017; Wolf \& McCoy, 2019), but in all cases EF and mathematics have an important place in pre-k skill development at home and in out-of-home programs.

Because many of the pre-k mathematics assessments have primarily measured numeracy, our understanding of the EF/pre-k mathematics connection is somewhat limited. The focus of this study is the longitudinal relationship among EF, numeracy, and geometry across rural and urban contexts. Separate measures of numeracy and geometry were utilized yielding separate scores for both domains of mathematics (TEAM A: numeracy \& TEAM B: geometry; Clements \& Sarama, 2011). The Process-Person-Context-Time (PPCT; Bronfenbrenner and Morris, 2006) provided the framework for this study. In addition to the person variables (gender, age) and family variables (parent/guardian income, education), the study involved families and preschools in rural and small urban areas (context). Abilities were measured fall and spring (time).

\section{Executive Functioning and Pre-K Mathematics}

$\mathrm{EF}$, including working memory, set-shifting, and inhibitory control, plays an essential 
role in cognition, educational attainment, emotion regulation, and social functioning (e.g., Morgan et al., 2019; Oberer, Gashaj, \& Roebers, 2018; Raver \& Blair, 2016). EF is essential for mental (e.g., Diamond, 2013) and physical (e.g., Miller, Barnes, \& Beaver, 2011) health, for school success (e.g., Duncan et al., 2007) and readiness (e.g., Best et al., 2011). There is some evidence that set-shifting tasks may be a better predictor of EF for younger pre-K children, working memory tasks for older pre-k children and kindergarteners, and inhibitory control tasks throughout the pre-k years and into kindergarten (Schmitt et al., 2017). Because of these findings, our EF measures involved working memory, shift, and inhibitory control tasks known to tap aspects of EF among younger and older preschool children.

Between ages 3 and 5 years, working memory (e.g., Ewing-Cobbs, Prasad, Landry, Kramer, \& DeLeon, 2004), inhibitory control, both simple (e.g., Lemmon \& Moore, 2007) and complex (e.g., Carlson, 2005), and set shifting, including attention (e.g., Hongwanishkul, Happaney, Lee, \& Zelazo, 2005) and response shifting (e.g., Espy, Kaufmann, Glisky, \& McDiarmid, 2001), are quickly changing and maturing. Variations in the rate of development can result in performance differences between children less than a year apart in age (e.g., Carlson, 2005; Deák, Rey, \& Pick, 2004; Müller, Dick, Gela, Overton, \& Zelazo, 2006). Gender is a significant factor in some EF studies, though not all (e.g., Deák et al., 2004). When gender differences are reported, preschool-age girls appear to have a modest advantage in latent EF assessments compared to boys (e.g., Denham, Bassett, Sirotkin, Brown, \& Morris, 2015; Wiebe, Espy, \& Charak, 2008) in performance on inhibitory control tasks (e.g., Bull, Espy, Wiebe, Sheffield, \& Nelson, 2011). In the studies cited above, direct assessments of EF were used (rather than parent and/or teacher report), and age was treated differently in each study. For example, Wiebe and colleagues (2008) found gender differences when they split their preschool- 
age sample into an older and younger group, while Deák and associates (2004) who did not find gender differences, kept their sample of three- to five- year-old children together in analyses. In this study the sample was divided into older and younger groups with the aim of understanding age and gender differences better.

Working memory (WM). Improvement in working memory (also known as updating; Simanowski \& Krajewski, 2019) between ages 3 and 5 years is documented for digit or word span tasks (e.g., Espy \& Bull, 2005), spatial or object span tasks (e.g., Ewing-Cobbs et al., 2004), spatial and object memory (e.g., Ewing-Cobbs et al., 2004), and tasks that assess the ability to track and update a number of items (e.g., Hongwanishkul et al., 2005).

Inhibitory control (IC). During the pre-k years, the act of restraining or withholding a motor response has received considerable attention. However, because of difficulties in designing a measure assessing only one aspect of EF, many inhibitory control tasks also involve working memory (Garon, Bryson, \& Smith, 2008). Tasks requiring minimal working memory input are simple task or wait tasks; those requiring moderate working memory input are complex tasks or choice tasks (Garon et al., 2008). Inhibition behaviors for both waiting and choice tasks usually improve across the pre-k period (e.g., Lemmon \& Moore, 2007) demonstrating the child's increasing ability to wait, plan, and modulate behavior. Similar to simple inhibitory tasks, age differences are evident between 3-year-olds and 5-year-olds (e.g., Wiebe et al., 2012) and between young threes (36-41 months) and older threes (42-47 months; Carlson, 2005). Both simple and complex inhibition tasks were administered in this study.

Set-shifting (Shift). Set-shifting demonstrates cognitive flexibility. It is dependent on working memory and inhibitory control operating on one another, making it the most complex aspect of the EF skills typically assessed during the preschool years (Chevalier et al., 2012). 
Demonstrating the complexity of set-shifting and the relatedness of all three aspects of EF, Bull and Scerif (2001) found that children with lower mathematical abilities scored lower on inhibition and working memory. In turn, the lower inhibition and working memory skills correlated with difficulty in set-shifting. Set-shifting tasks include attention shifting, where the rules change based on an aspect of the stimuli (color, shape, etc.), and response shifting, where a new motor response is required (Rushworth, Passingham, \& Nobre, 2005). In this study two setshifting measures were administered to measure both attention and response shifting.

Mathematics skills (usually numeracy) and EF develop throughout the preschool years (e.g., Purpura, Schmitt, \& Ganley, 2017; Schmitt et al., 2017; Wolf \& McCoy, 2019) and influence a child's academic achievement in kindergarten and into grade school (e.g., Nesbitt, Fuhs, \& Farran, 2019; Nguyen \& Duncan, 2019; Simanowski \& Krajewski, 2019). Few significant pre-k gender differences are reported in mathematics performance (Corrington, 2008; Ganley \& Lubienski, 2016), and upon kindergarten entry, girls score the same as boys (Robinson \& Lubienski, 2011) or higher (Corrington, 2008). However, as elementary school progresses, boys begin to score better than girls (Robinson \& Lubienski, 2011).

Links between early mathematics performance and EF during the preschool years are well established (e.g., Nesbitt et al., 2019; Purpura et al., 2017; Schmitt et al., 2017). There is even evidence that $\mathrm{EF}$ at age two years may later predict mathematics understanding at school entry (Mulder, Verhagen, Van der Ven, Slot \& Leseman, 2017).

Some researchers report that all three EF processes (working memory, shift, and inhibitory control) are related to mathematical performance (e.g., Purpura et al., 2017); in other studies, working memory and inhibitory control are more consistently connected to preschool mathematic performance (e.g., Clements et al., 2016; Espy et al, 2004; McClelland et al., 2007). 
Links have also been found between mathematics, inhibitory control, and set-shifting (e.g., Blair \& Razza, 2007).

Although much of the literature discusses EF-mathematics connections, many studies focused specifically on numerical skills, including knowing, comparing, and ordering numbers and "doing" simple operations rather than aspects of mathematics including number and operations, measurement, patterning, and geometry (Milburn, Lonigan, DeFlorio, \& Klein, 2019). One research group (Eden \& Potter, 2013) found no relationship between geometry and teacher ratings of children's self-regulation, but to our knowledge, EF-geometry links have otherwise received little attention. Our expectation in this study was that EF-geometry connections would change across the preschool years similar to the changes in the EF-numeracy connection (e.g., Fuhs et al., 2014; Jacob \& Parkinson, 2015; Schmitt et al., 2017). We conjectured that given the differences between numeracy and geometry, there would likely be EF measures more predictive of the variance in one area of mathematics than the other. We also expected to see age differences in the EF-geometry relationship since they are evident in the EFnumeracy relationship for younger and older pre-k children.

\section{Assessment}

Creating developmentally appropriate pre-k EF measures is a challenge (Carlson, 2005) as many adult assessments of EF are too linguistically demanding (Hughes \& Graham, 2002) or involve complex tasks that, when simplified for young children, no longer measure the targeted EF component (Garon et al., 2008). Our aim was to use assessments sensitive to manifestations of EF in typically functioning children about 36-months-old and robust across development to about 60 months. We also wanted to use measures that in most cases could be replicated in preschool settings for developmental assessments or as a game. In order to maximize detection 
of EF, numeracy, and geometry links across contexts and ages, multiple measures with different assessment strategies were involved. Five direct EF measures were selected, including a working memory measure, two set-shifting assessments, and two inhibition assessments. Additionally, preschool teachers completed an indirect measure of EF for each child assessing all three elements of EF investigated in this study. Research continues to refine EF measures, with recent work suggesting that adding motor components to EF assessments might enhance pre-k performance (Rhoads, Miller, \& Jaeger, 2018). One of the measures selected contained an active motor component while several others involved more minimal motor movements.

\section{Context and Time within the PPCT Framework}

One of the most common ways to measure context is by assessing socioeconomic status (SES). For example, low SES relates to both lower EF (e.g. St. John, Kibbe, \& Tarullo, 2019) and mathematics scores (e.g. Bachman, Degol, Scharphorn, Nokali, \& Palmer, 2018). The ruralurban context has received less attention, but extant literature suggests significant differences exist by rural-urban settings relative to pre-k mathematics development (e.g. Miller \& VotrubaDrzal, 2013). This finding has particular importance for state or regional-level directors responsible for child programs across a variety of contexts. Urban children tend to outscore their suburban and rural peers on kindergarten mathematics (Hermida, et al., 2019), and this advantage persists and broadens over the school years (Graham \& Provost, 2012). When urbanicity is divided into large urban, small urban, and rural designations, kindergarten children in small urban areas outscore large urban and rural children on mathematics (Miller \& VotrubaDrzal, 2013; Miller et al., 2013). To our knowledge, geometry has received less frequent attention for rural and urban pre-k populations. Likewise, EF seems less consistently studied across the urban-rural context, but it appears the same differences exist for EF with urban 
children scoring higher than their rural peers (Hermida, et al., 2019).

Rural-urban differences have been attributed to a number of variables including family income (e.g., O'Hare et al., 2013) and education (e.g., Provasnik et al., 2007). However, income appears to have the greatest positive impact on early academic skills in large urban areas rather than small urban, suburban, or rural contexts (Miller et al., 2013). Quality of home environment and positive parenting practices also vary across the rural-urban context with urban areas typically scoring higher than rural areas (e.g., Hackman, Gallop, Evans, \& Farah, 2015; Miller \& Votruba-Drzal, 2013; Provasnik et al., 2007). Rural parents appear to have lower academic expectations for their children as well as minimal knowledge of child development (Miller et al., 2013). Rural children are less likely to attend preschool, and rural primary and secondary schools have fewer cash resources than other schools for augmenting teacher salaries, sponsoring teacher trainings, or purchasing extra teaching materials (Graham \& Provost, 2012). The rural-urban context, although understudied relative to young children's EF, numeracy, and mathematics skills, appears to be a significant and complex variable given its relationship to early childhood cognitive development.

Given the relatively slim number of studies on EF, numeracy, and geometry and the salience of the rural-urban context to early childhood development, this study had the following aims:

\section{Research Questions}

1. How are the various executive function measures and the measure of mathematical performance (numeracy and geometry) related to one another? 
2. Are there differences in the amount of variance claimed by various executive function assessment strategies (single measure, direct panel, direct panel and indirect measure) on preschool-age mathematical performance (numeracy and geometry)?

3. Do the differences in the amount of variance claimed by various executive function assessment strategies change by age, gender, or rural-urban context?

\section{Methods}

\section{Participants}

Children, their parents, and childcare providers were recruited from rural and urban areas in the western United States. The rural-urban context was determined by the Rural-Urban Continuum Codes (USDA, 2013). Rural participants were recruited from areas categorized as a 7 (counties with a population less than 20,000), while urban participants were from areas categorized as a 3 (a metro area with a population between 20,000 and 250,000). Participants were recruited from state-licensed child care centers operating in rural (four centers; $n=64$ ) and urban (three centers; $n=54$ ) areas.

\section{Measures}

Direct measures of EF. At both testing periods all five direct measures were given within one week's time and were administered individually. In order to avoid order effects, the order of assessments was randomized to prevent the administration of similar measures consecutively.

Dimensional Change Card Sort (DCCS). The DCCS (Frye, Zelazo, \& Palfai, 1995; Zelazo, 2006) is a nonverbal task requiring attention shifting between two rule sets. Children are required to sort a series of bivalent test cards, first by one dimension (color), then by the other (shape). Completion time for both pre-switch and switch trials is five minutes. Zelazo and 
colleagues (2013) demonstrated convergent validity for the DCCS through positive correlations for three- to six-year-olds, $r(74)=.69, p<.0001$ with the Block Design subtest of the Wechsler Preschool and Primary Scale of Intelligence, 3rd Edition (WPPSI-III; Wechsler, 2002), a measure of fluid cognition normally highly correlated with EF (e.g., Blair, 2006). The test-retest intraclass correlation coefficient (ICC) for the DCCS is .92 (Zelazo et al., 2013).

The DCCS involves all three aspects of EF: set-shifting between two rule sets, inhibitory control to suppress following the previous rule, and working memory to remember relevant rules (Buss \& Spencer, 2014). Based on the descriptions of types of EF assessment by Garon and associates (2008), in this study the DCCS is classified as a measure of attention set-shifting.

Head Toes Knees Shoulders (HTKS). The HTKS uses motor skills to measure EF through response shifting. Children are asked to play a game in which they must do the opposite of the usual rules and do the opposite of what the experimenter says. Before the trials the experimenter tells children that if they are told to touch their head, they must touch their toes, and vice-versa. A more advanced trial adds knees and shoulders commands. The HTKS takes approximately 5-7 minutes to administer and has strong inter-rater reliability (kappa $=0.90$; McClelland \& Cameron, 2012; Ponitz, McClelland, Matthews, \& Morrison, 2009). McClelland and associates (2014) found the HTKS correlated with the DCCS $(r=0.56)$ and to a measure of working memory $(r=0.60$; Auditory Working Memory test from the Woodcock-Johnson III; Woodcock et al., 2001). Based on the descriptions of types of EF assessment by Garon and associates (2008), in this study the HTKS is classified as a measure of complex inhibitory control, as working memory is a moderate component of this measure.

Porteus Maze Test, Vineland version (PMT). The PMT (Porteus, 1965) is a nonverbal assessment of EF (e.g., Gow \& Ward, 1982; Krikorian \& Bartok, 1998; Tuvblad, May, Jackson, 
Raine, \& Baker, 2017), where the participant works through a series of mazes of increasing difficulty, drawing a line from the entrance of the maze to the exit. The examiners script was followed for each maze with instructions to avoid the following: dead ends, lifting the pencil from the paper, and crossing over solid lines. For preschool children, scoring allowances were made for poor motor control (Porteus, 1965). In this study, participants started with the maze designed for three-year-old children (Year III) and could advance to one designed for 10-yearolds (Year X). Internal consistency was reported by Krikorian and Bartok (1998; Cronbach’s alpha $=.81)$, with completion time between 10 and 15 minutes. Divergent validity was demonstrated as the PMT accounted for a majority of the error variance with intelligence tests (Spreen \& Strauss, 1998). Congruent validity $(r=.424)$ was found with the Matching Familiar Figures Test (Kagan, Rosman, Day, Albert, \& Phillips, 1964), a measure of impulse control (Gow \& Ward, 1982). The PMT was used as a measure of simple inhibitory control, as working memory is a minimal component of this measure (Garon et al., 2008).

Tower of Hanoi (TOH). The TOH (Klahr, 1978; Simon, 1975) is a nonverbal assessment of EF and was administered following the outline described by Bull, Espy, and Senn (2004). This outline used the Welsh, Pennington, and Groisser (1991) version of the TOH, the instructional story from Klahr and Robinson (1981) but simplified the Welsh et al. (1991) version by presenting a single trial for each of six problems, requiring two to seven moves to solve. Testretest reliability has ranged from .53-.72, depending on the length of the interval between retesting (Bull et al., 2004). In this study the $\mathrm{TOH}$ is classified as a measure of response setshifting (Garon et al., 2008).

Forward-Digit Span. The use of forward-digit span as a verbal measure of working memory for preschool-age children is well established (e.g., Klingberg, 2010; Snyder, Kaiser, 
Warren, \& Heller, 2015; Wiebe et al., 2008). After a practice session, the experimenter repeated digits at the rate of approximately one digit every 2 seconds, starting with a span length of two and increasing number of digits as the trials continued. Digit span test-retest reliability ranged from .85-.87 (Gray, 2003), and is significantly correlated with the Children's Test of Nonword Repetition (CNRep; Gathercole, Willis, Baddeley, \& Emslie, 1994; $r=.524$ to .667; Gathercole, Willis, \& Baddeley, 1991).

Indirect measure of EF. The Behavior Rating Inventory of Executive FunctionPreschool Version (BRIEF-P) is completed by an adult familiar with the child's behaviors, usually a childcare provider, preschool teacher, or guardian. It consists of 63 items that measure EF in five nonoverlapping theoretically and empirically supported subscales: Inhibit, Shift, Emotional Control, Working Memory, and Plan/Organize (Gioia, Espy, \& Isquith, 2003). BRIEF-P subscales can be combined to form three broader indices and an overall score, the Global Executive Composite (GEC). For teacher normative samples, the internal consistency was .90-.97 and the test-retest reliability was .65-.94 (Isquith, Crawford, Espy, \& Gioia, 2005).

\section{Numeracy and geometry measures.}

Tools for Early Assessment in Math (TEAM) The TEAM, divided into two separate assessments for numeracy (TEAM A) and geometry (TEAM B), uses a multi-manipulative, direct interview format (Clements \& Sarama, 2011). TEAM A focuses on numbers (e.g., number recognition, sequencing, and comparison; verbal and object counting; adding and subtracting, etc.) and TEAM B focusing on shapes (e.g., shape recognition, composition, and decomposition; construction of shapes and patterns; spatial imagery, etc.). Each part takes about 10-20 minutes to administer. Parts A and B were given in a random order and were not administered consecutively but had at least one other measure presented in between. Concurrent validity was 
established with the Child Math Assessment: Preschool Battery $((r=.86$; Klein, Starkey, \& Wakeley, 2000). For this sample, test-retest reliability after about six months $=.82$ (TEAM A), .54 (TEAM B).

\section{Demographic Measures.}

Parent demographic questionnaire. The parent demographic questionnaire had 25-items covering parent education, gender, income, and ethnicity.

Teacher demographic questionnaire. The teacher demographic questionnaire had 15items that covered education, experience in childcare, and ethnicity.

\section{Procedure}

All measures were given at Time 1 (T1) and Time 2 (T2). T1 measures were given at the beginning of the school year. T2 measures were repeated about six months later $(M=5.61$ mos., $S D=1.12$ ). Children responded to the direct executive function measures and TEAM A and TEAM B. Teachers completed the BRIEF-P and the teacher demographic questionnaire. Parents completed the parent demographic questionnaire. Data collection was overseen by two project co-managers who maintained item-level interrater reliability of .90 or above during both assessment periods. Undergraduate research assistants were recruited in rural (T1 and T2 = 3) and urban $(\mathrm{T} 1=5 ; \mathrm{T} 2=2)$ areas. Two additional research assistants worked in both rural and urban areas. Prior to data collection research assistants were trained on measures with randomized item-level reliability checks throughout the data collection periods. Because of its complexity, TEAM A and TEAM B were only administered by project co-managers.

\section{Results}

At T1, 64 rural children (33 girls) ranging in age from 40 to 63 months $(M=51.61, S D=$ 6.32) and 54 urban children ( 26 girls) ranging in age from 39 to 68 months $(M=53.72, S D=$ 
6.24) participated. At T2, 55 rural children ( 28 girls) ranging in age from 47 to 69 months ( $M=$ $58.35, S D=6.26)$ and 53 urban children ( 25 girls) ranging in age from 45 to 72 months $(M=$ $58.68, S D=5.96)$ participated. Participants were primarily Caucasian. No significant difference in child age was found between rural and urban samples at $\mathrm{T} 1(t[116]=-1.82, p=.07)$ or $\mathrm{T} 2$ $(t[106]=-.28, p=.77)$. Although significant differences for parent education were found by rural-urban context, income differences between groups were nonsignificant (see Table 1). Providers were female, predominately Caucasian, about 39-years-old $(M=39.44, S D=12.97)$, and averaged about 13 years in the childcare industry $(M=13.46, S D=8.08)$. Rural providers' $(\mathrm{n}=10)$ highest level of education included high school/GED (4), CDA (1), technical degree (1), 4 year-college degree (3), and Master's Degree (1). Urban providers' $(n=6)$ highest level of education included CDA (1), two-year associates degree (2), four-year college degree (2), and Master's Degree (1).

Question 1: How are the executive function measures and the measures of mathematical performance (numeracy and geometry) related to one another?

Correlations were run (Table 3) between the dependent (numeracy and geometry) and independent variables (DCCS, TOH, digit span, PMT, HTKS, BRIEF-P).

At T1, numeracy and geometry were significantly correlated, indicating the two aspects of mathematics skills are related $(r=.49, p<.001)$. Correlations between EF measures and numeracy skills were larger than those between EF measures and geometry. Only moderate correlations were found among EF measures $(r=.44, p<.001)$ suggesting the EF measures targeted different but related processes.

At $\mathrm{T} 2$, numeracy skill and geometry skill were more highly correlated than at $\mathrm{T} 1(r=.63$, $p<.001)$. There were significant correlations among all direct EF measures and both numeracy 
and geometry skills (Table 3, bottom diagonal). At T2 the BRIEF-P was no longer significantly correlated with either numeracy skill or geometry skill.

Question 2: Are there differences in the amount of variance claimed by executive function assessment strategies (single measure, direct panel, direct panel and indirect measure) on preschool-age mathematical performance (numeracy and geometry)?

To explore question 2 a hierarchical regression was conducted with multiple blocks to identify differences in the predictive power of the three strategies. The first block included demographic variables (gender, rural-urban context, and age), the second block added a solitary EF measure (DCCS, selected due to its frequency of use in the literature), the third block added the remaining direct EF measures (TOH, forward digit span, PMT, HTKS), and the final block added the indirect EF measure (BRIEF-P).

Hierarchal regressions were run with all direct EF measures in the second block (e.g., demographic variables + HTKS, demographic variables + TOH, etc.; Table 4). At T1 the digit span had the greatest beta $(\beta=.33, p<.001)$ and explaining the largest amount of variance $\left(R^{2}=\right.$ $.43)$ in numeracy skill. At T2 the digit span had one of the lowest reported betas $(\beta=.19, p<$ $.05)$ and the lowest R-square $\left(R^{2}=.36\right)$, while the HTKS explained the greatest variance in numeracy $\left(R^{2}=.43\right)$.

Hierarchical regressions repeated for geometry skills showed fewer significant predictors (Table 4). At T2 several measures became better solitary predictors of geometry skill compared with T1, with the HTKS predicting the most variance at T2.

The panel of direct EF measures was added to the hierarchical regressions to identify differences in the amount of variance claimed by the use of a panel of measures at $\mathrm{T} 1$ and $\mathrm{T} 2$ for numeracy skill (Table 5) and geometry skill (Table 6). For both numeracy and geometry, 
multicollinearity ranged from .85 to .57 , well above the 0.20 threshold (Hair, Hult, Ringle, \& Sarstedt, 2014).

Adding the panel of direct measures had a significant $\Delta R^{2}$ and accounted for $54 \%$ of the variance in numeracy at $\mathrm{T} 1$ and accounted for $51 \%$ of the variance at $\mathrm{T} 2$.

For geometry skill at T1 (Table 6), the panel of direct measures did not have a significant $\Delta R^{2}$ at T1 and accounted for $26 \%$ of the variance. Only one EF measure had a significant beta: $\operatorname{DCCS}(\beta=.21, p<.05)$. At T2 the panel of direct measures had a significant $\Delta R^{2}$ and accounted for $39 \%$ of the variance in geometry performance. At T2, a solitary EF measure had a significant beta: the HTKS $(\beta=.38, p<.001)$.

Adding block 3 with the indirect measure of EF (BRIEF-P) did not have a significant $\Delta R^{2}$ for either numeracy or geometry skill in this sample. The BRIEF-P was excluded from future analyses.

\section{Question 3: Do the differences in the amount of variance claimed by various executive function assessment strategies change by age, gender, or rural-urban context?}

To further examine the influence of age the total sample was split at the mean age $(52.58$ months, Table 7). The demographic variable of gender was removed for non-significance. The second block added the DCCS and the third added the panel of direct EF measures. The sample split at the mean age created four groups (younger: T1 and T2; older: T1 and T2). The ruralurban context (block 1) was a significant predictor of numeracy at T1 for both younger and older children but was not significant for geometry.

For the younger children the DCCS explained $37 \%$ of the variance in numeracy skill at T1 and 19\% at T2 (Table 8). The PMT and HTKS were significant predictors of numeracy skill for all four groups, although, similar to the analyses for Q2, fewer EF variables predicted 
geometry than numeracy skill. The DCCS again had the greatest beta at T1 for numeracy and geometry, but for geometry it was significant only for the youngest children (younger, T1). Both PMT and HTKS were significant predictors of geometry skill for three of four groups, with HTKS predicting the greatest amount of the variance for older children at both time points. The three blocks of variables were regressed on geometry skill for the four groups (younger: T1 and T2; older: T1 and T2) for a total of four hierarchical regressions (Table 9). Adding block 3 resulted in a significant $\Delta R^{2}$ for all but the younger children at T2. For numeracy and geometry, multicollinearity was not an issue as tolerance levels ranged from 1.00 to .57 , above the 0.20 threshold (Hair et al, 2014).

\section{Discussion}

\section{Question 1: How are the various executive function measures and the measure of mathematical performance (numeracy and geometry) related to one another?}

Correlations between TEAM A and TEAM B indicate that numeracy and geometry are highly related but with independent elements. The larger correlation at T2 suggests that as numeracy and geometry skills improve across time, they become more connected, likely drawing upon similar cognitive abilities. Contrary to Eden and Potter (2013), all EF measures except the BRIEF-P were significantly correlated with both numeracy and geometry. However, EF in the Eden and Potter study was measured using teacher report and not direct assessment, so this likely explains the nonsignificant findings between EF and geometry.

Given the pattern of correlations, we suspect geometry may be more closely linked to inhibitory control than other EF skills. Perhaps "doing geometry" requires the inhibition of initial responses, giving the student time to think about nonintuitive responses to a problem. Working memory may play a part (e.g., remembering pattern, requested shape, etc.), likely because with 
an inhibition of response the student must remember what does not work in order to discover what works.

Question 2: Are there differences in the amount of variance claimed by various executive function assessment strategies (single measure, direct panel, direct panel and indirect measure) on preschool-age mathematical performance (numeracy and geometry)?

A single measure assessment strategy utilized in the first two blocks of the hierarchical regressions isolated the influence of separate EF measures on numeracy and geometry. For numeracy, the digit span had the largest beta at $\mathrm{T} 1$ but one of the smallest betas at $\mathrm{T} 2$, likely indicating the developmental changes occurring in cognitive skills across a six-month period.

The DCCS is commonly used in pre-k studies as a singular measure of EF (e.g., Buss \& Spencer, 2014). For this sample, the DCCS as a solitary EF measure was more useful at T1, given the percent of variance explained. This finding raises the question of whether, for some children, a non-number-based EF activity, similar to the DCCS, is more useful with children who have had less practice with numbers or have forgotten some of their numeracy skills across the summer.

Compared to the relationship between EF and numeracy skills, the EF measures explained less of the variance in geometry skills. Given that the DCCS focuses on visual discrimination, it is not surprising that it explained the most variance in geometry at $\mathrm{T} 1$.

At T2, EF measures accounted for more of the variability in geometry yet still explained less of the variance compared to T2 numeracy. The measure of complex inhibitory control (HTKS) and the measure of simple inhibitory control (PMT), claimed the most variance at T2. The HTKS, in fact, explained more than double the percent of variability at $\mathrm{T} 2$ than $\mathrm{T} 1$, suggesting the importance of inhibitory control in solving pre-k geometry problems. 


\section{Question 3: Do the differences in the amount of variance claimed by various executive function assessment strategies change by age, gender, and rural-urban context?}

The sample was split into younger and older groups at the sample mean age (52.58 months), a strategy supported by extant literature (e.g., Bull et al., 2011; Wiebe et al., 2008). This age split created four non-independent groups (younger: T1 and T2; older: T1 and T2).

Rural-urban context was a significant predictor of numeracy for both younger and older children at T1, supporting other studies that found school readiness disparities between rural and urban children at the start of the school year (e.g., Miller \& Votruba-Drzal, 2013).

Statistically significant income differences were not found between rural-urban contexts in this sample, and the differences in scores may be a result of differences in contextual opportunities (Bronfenbrenner \& Morris, 2006), quality of home environment and parenting practices (e.g., Hackman, Gallop, Evans, \& Farah, 2015; Miller \& Votruba-Drzal, 2013; Provasnik et al., 2007), and/or rural parents' academic expectations and knowledge of child development (Miller, et al. 2013). Rural schools are often under resourced (Graham \& Provost, 2012), and educational and cultural opportunities may be scarce, factors that could limit cognitive development.

With four non-independent groups about six months apart, developmental changes become apparent. With the age split, the DCCS as a single measure of EF in predicting numeracy performance is most effective with younger children. The TOH was significant only for older children. The PMT and HTKS were more "universal" measures in our study, being significant predictors of numeracy for younger and older children at both time points.

The HTKS explained the greatest amount of variance in geometry skill across the four groups. Based on these results, when selecting a singular measure of EF the HTKS appears to be 
the best assessment for predicting geometry skill for older children followed by the DCCS. Similarly, when designing pre-k activities at home and in the classroom, both HTKS and DCCS types of activities appear to relate to the largest age span.

Even though the HTKS appears to be the best choice for assessing both numeracy and geometry, in this study there was a six-month period where it is a better assessment of numeracy skill than geometry skill. This may be because the geometry-EF link develops later or that children are more comfortable solving numeracy rather than geometry problems, perhaps because of their relative exposure to each.

The panel of direct EF measures made significant improvements on model fit for predicting numeracy and geometry skill, but only for the older children, supporting previous work suggesting that older children have developed more aspects of EF (e.g., Clark et al., 2016). This finding was not seen when the children were grouped together; thus, to capture the most variability in numeracy and geometry performance in a sample older than 52.58 months, a panel of direct EF measures seems more efficient.

Beyond comparisons of analytic strategy, these results also demonstrate how easy it is for scholars' findings to differ. As previously reported (Carlson, 2005), assessments occurring even within a year can show dramatic EF improvement. An example from the current study is the digit span, which was highly predictive at $\mathrm{T} 1$ of numeracy performance but about six months later was not statistically significant. This finding also suggests that in mixed-age pre-k groups, using a digit span game, or any EF-type game, might be engaging or supportive of growth for some children but not for others.

Finally, multicollinearity between the five direct EF measures was not an issue for any of the regressions or correlations. While each measure was selected to measure EF in differing 
ways, stronger statistical relationships between measures would be expected if they were all measuring a single construct, rather than unique but interrelated aspects. While this does not solve the unitary vs. componential EF debate, it does suggest value in utilizing multiple EF measures, and, in the preschool classroom giving children experience with different types of EF activities.

\section{Conclusion}

\section{Limitations}

Although this study makes a unique contribution, there are limitations to address. Difficulties in gathering longitudinal data, especially from a rural area as distant as the one assessed, resulted in missing data. Between T1 and T2 nine rural participants, $14.1 \%$ of rural sample, were lost due to parents' losing a job and/or moving out of the area. In comparison, only one urban participant, $1.9 \%$ of urban sample, was lost. However, $t$ tests found no statistically significant differences on any of the variables used in analyses between those who remained in the study and those who did not.

Sample size prevented more advanced statistical analyses as well as in-depth analyses between groups. In this study the urban area had more centers than the rural area, but it was harder to recruit the urban sample. Likely it had to do with center director fatigue in participating in research, since there were a large number of ongoing childcare studies during the recruitment year. Rural providers and parents were eager to participate, but it was more difficult getting rural parents to return assessment materials. The practical issue of winter weather driving conditions impacted data collection. The rural area is isolated by mountains that received a large number of blizzards during the data collection process. Although efforts were made to recruit a data 
collection team in the rural area, the training requirements for the TEAM and the time commitment for the assessors made it impossible to do so.

\section{Contributions, Implications, and Future Research}

Many scholars have examined the relationships between pre-k EF and numeracy skill, but this is one of the first study of its kind, to our knowledge, to compare various EF assessment strategies in predicting both numeracy and geometry skill across two age points with rural and urban populations.

The assessments used offer valuable insight for practitioners and parents. The DCCS, a card sort game related to numeracy development, appears most useful for children below age 52.58 months. Above this age, the HTKS becomes significantly linked with numeracy and geometry. The results of this study suggest that utilizing a panel of EF measures to predict mathematics skill may be inefficient unless the sample is older. There is some suggestion that the EF-geometry link may develop later than numeracy by about six months, but future studies will need to replicate these findings to determine if it is an artifact of current instrumentation or merely a reflection of classroom or parent teaching practices.

The current study supports previous work indicating significant mathematics skill differences between rural and urban samples (e.g., Miller \& Votruba-Drzal, 2013) that are unrelated to differences in income. These results are particularly important to state and regional early childhood directors who work across urban and rural areas, legislators and policymakers, teachers and parents. If teachers and parents in rural areas adopt more math focused activities, a technique shown to help children make large gains in mathematics skills (de Hann, Elbers, \& Leseman, 2014), students might be able to overcome the contextual challenges to mathematics skills development they face. 
Acknowledgments: We would like to thank the [Redacted] Agricultural Experiment Station for financial support of this research. Thanks also to Dr. [Redacted] for his role as data manager and to Ms. [Redacted] for her role as a graduate research assistant.

Declaration of Interest Statement: No potential conflict of interest was reported by the authors. 


\section{References}

Bachman, H. J., Degol, J. L., Elliott, L. Scharphorn, N. E., Nokali, E. L., \& Palmer, K. M. (2018). Preschool math experience in private center-based care and low-SES children's math development. Early Education and Development, 29(3), 417-434. doi:10.1080/10409289.2017.1406245

Best, J. R., Miller, P. H., \& Naglieri, J. A. (2011). Relations between executive function and academic achievement from ages 5 to 17 in a large, representative national sample. Learning and Individual Differences, 21(4), 327-336. doi:10.1016/j.lindif.2011.01.007.

Blair, C. (2006). How similar are fluid cognition and general intelligence? A developmental neuroscience perspective on fluid cognition as an aspect of human cognitive ability. Behavioral and Brain Sciences, 29, 109-125. doi:10.1017/S0140525X06009034

Blair, C., \& Razza, R. P. (2007). Relating effortful control, executive function, and false belief understanding to emerging math and literacy ability in kindergarten. Child Development, 78, 647-663. doi:10.1111/j.1467-8624.2007.01019.x

Bronfenbrenner, U. (1979). The ecology of human development: Experiements by nature and design. Cambridge, MA: Harvard University Press. doi:10.1080/00131728109336000

Bronfenbrenner, U., \& Morris, P. A. (2006). The bioecological model of human development. In R. M. Lerner (Ed.), Handbook of child psychology: Vol. 1: Theoretical models of human development (pp. 793-828). (6 $6^{\text {th }}$ ed.). Hoboken, NJ: Wiley.

Bull, R., Espy, K. A., \& Senn, T. E. (2004). A comparison of performance on the Towers of London and Hanoi in young children. Journal of Child Psychology and Psychiatry, 45(4), 743-754. doi:10.1111/j.1469-7610.2004.00268.x

Bull, R., Espy, K. A., Wiebe, S. A., Sheffield, T. D., \& Nelson, J. M. (2011). Using confirmatory 
factor analysis to understand executive control in preschool children: Sources of variation in emergent mathematic achievement. Developmental Science, 14(4), 679-692. doi:10.1111/j.1467- 7687.2010.01012.x

Bull, R., \& Scerif, G. (2001). Executive functioning as a predictor of children's mathematics ability: Inhibition, switching, and working memory. Developmental Neuropsychology, 19, 273-293. doi:10.1207/S15326942DN1903_3

Buss, A. T., \& Spencer, J. P. (2014). The emergent executive: A dynamic field theory of the development of executive function. Monographs of the Society for Research in Child Development, 79(2), vii.

Carlson, S. M. (2005) Developmentally sensitive measures of executive function in preschool children, Developmental Neuropsychology, 28(2), 595-616, doi:10.1207/s15326942dn2802_3

Chevalier, N., Sheffield, T. D., Nelson, J. M., Clark, C. A. C., Wiebe, S. A., \& Espy, K.A. (2012). Underpinnings of the costs of flexibility in preschool children: The roles of working memory and inhibition. Developmental Neuropsychology, 37, 99-118. doi:10.1080/87565641.2011.632458

Clark, C. A. C., Chevalier, N., Nelson, J. M., James, T. D., Garza, J. P., Choi, H. J., \& Espy, K. A. (2016). The changing nature of executive control in preschool: I. Executive control in early childhood. Monographs of the Society for Research in Child Development, 81(4), 729. doi:10.1111/mono. 12268

Clements, D. H., \& Battista, M. T. (1992). Geometry and spatial reasoning. Handbook of research on mathematics teaching and learning, 420-464.

Clements, D. H., \& Sarama, J. (2011). TEAM: Tools for early assessment in math-teachers 
guide. Columbus, OH: McGraw-Hill.

Clements, D. H., Sarama, J., \& Germeroth, C. (2016). Learning executive function and early mathematics: Directions of causal relations. Early Childhood Research Quarterly, 36, 7990. doi:10.1016/j.ecresq.2015.12.009

Clements, D. H., Sarama, J. H., \& Liu, X. H. (2008). Development of a measure of early mathematics achievement using the Rasch model: The Research-Based Early Maths Assessment. Educational Psychology, 28(4), 457-482. doi:10.1080/01443410701777272

Corrington, M. E. (2008). Understanding gender differences in the effects of the Tulsa pre-k program on school readiness (master's thesis). Retrieved from https://repository.library.georgetown.edu/handle/10822/555895?show=full

Deák, G. O., Rey, S. D., \& Pick, A. D. (2004). Effects of age, reminders, and task difficulty on young children's rule-switching flexibility. Cognitive Development, 19, 385-400. doi:10.1016/j.cogdev.2004.05.002

de Haan, A. K. E., Elbers, E., \& Leseman, P. P. (2014). Teacher-and child-managed academic activities in preschool and kindergarten and their influence on children's gains in emergent academic skills. Journal of Research in Childhood Education, 28(1), 43-58. doi:10.1080/02568543.2013.851750

Denham, S. A., Bassett, H. H., Sirotkin, Y. S., Brown, C., \& Morris, C. S. (2015). "No-ooo peeking": Preschoolers' executive control, social competence, and classroom adjustment. Journal of Research in Childhood Education, 29(2), 212-225. doi:10.1080/02568543.2015.1008659

Diamond, A. (2013). Executive functions. Annual Review of Psychology, 64, 135-168. doi:10.1146/annurev-psych-113011-143750 
Duncan, G. J., Dowsett, C. J., Claessens, A., Magnuson, K., Huston, A. C., Klebanov, P., \& Sexton, H. (2007). School readiness and later achievement. Developmental Psychology, 43(6), 1428-1446. doi:10.1037/0012-1649.43.6.1428

Eden, K. M. \& Potter, E. F. (2013) An exploratory look at the relationships among math skills, motivational factors and activity choice, Early Childhood Education Journal, 41, 235243. doi:10.1007/s10643-012-0540-y

Espy, K. A., \& Bull, R. (2005). Inhibitory processes in young children and individual variation in short-term memory. Developmental Neuropsychology, 28, 669-688. doi:10.1207/s15326942dn2802_6

Espy, K. A., Kaufmann, P. M., Glisky, M. L., \& McDiarmid, M. D. (2001). New procedures to assess executive functions in preschool children. Clinical Neuropsychologist, 15, 46-58. doi:10.1076/clin.15.1.46.1908

Ewing-Cobbs, L., Prasad, M. R., Landry, S. H., Kramer, L., \& DeLeon, R. (2004). Executive functions following traumatic brain injury in young children: A preliminary analysis. Developmental Neuropsychology, 26(1), 487-512. doi:10.1207/s15326942dn2601_7

Frye, D., Zelazo, P. D., \& Palfai, T. (1995). Theory of mind and rule-based reasoning. Cognitive Development, 10, 483-527. doi:10.1016/0885-2014(95)90024-1

Fuhs, M. W., Nesbitt, K. T., Farran, D. C., \& Dong, N. (2014). Longitudinal associations between executive functioning and academic skills across content areas. Developmental Psychology, 50(6), 1698-1709. doi:10.1037/a0036633.

Ganley, C. M. \& Lubienski, S. T. (2016). Mathematics confidence, interest, and performance: Examining gender patterns and reciprocal relations. Learning and Individual Differences, 47, 182-193. doi:10.1016/j.lindif.2016.01.002 
Garon, N., Bryson, S. E., \& Smith, I. M. (2008). Executive function in preschoolers: A review using an integrative framework. Psychological Bulletin, 134(1), 31-60. doi:10.1037/0033-2909.134.1.31

Gathercole, S. E., Willis, C., \& Baddeley, A. D. (1991). Differentiating phonological memory and awareness of rhyme: Reading and vocabulary development in children. British Journal of Psychology, 82, 387-406. doi:10.1111/j.2044-8295.1991.tb02407.x

Gathercole, S. E., Willis, C. S., Baddeley, A. D., \& Emslie, H. (1994). The Children's Test of Nonword Repetition: A test of phonological working memory. Memory, 2, 103-127. doi:10.1080/09658219408258940

Gioia, G. A., Espy, K. A., \& Isquith, P. K. (2003). BRIEF-P: Behavior Rating Inventory of Executive Function--Preschool Version: Professional Manual. Odessa, FL: Psychological Assessment Resources.

Gow, L., \& Ward, J. (1982). The Porteus Maze Test in the measure of reflection/impulsivity. Perceptual and Motor Skills, 54, 1043-1052.

Graham, S. E. \& Provost, L. E. (2012, Summer). Mathematics achievement gaps between suburban students and their rural and urban peers increase over time (Issue Brief no. 52). Durnham, NH: Carsey Institute.

Gray, S. (2003). Diagnostic accuracy and test-retest reliability of nonword repetition and digit span tasks administered to preschool children with specific language impairment. Journal of Communication Disorders, 36(2), 129-151. doi:10.1016/S0021-9924(03)00003-0

Hackman, D. A., Gallop, R., Evans, G. W., \& Farah, M. J. (2015). Socioeconomic status and executive function: developmental trajectories and mediation. Developmental Science, 18(5), 686-702. doi:10.1111/desc. 12246 
Hair, J. F., Hult, G. T. M., Ringle, C., \& Sarstedt, M. (2014). A primer on partial least squares structural equation modeling (PLS-SEM). London, England: Sage Publications.

Hermida, M. J., Shalom, D. E., Segretin, M. S., Goldin, A. P., Abril, M. C., Lipina, S. J., \& Sigman, M. (2019). Risks for child cognitive development in rural context. Frontiers in Psychology, 9:2735. doi:10.3389/fpsyg.2018.02735.

Hongwanishkul, D., Happaney, K. R., Lee, W. S., \& Zelazo, P. D. (2005). Assessment of hot and cool executive function in young children: Age-related changes and individual differences. Developmental Neuropsychology, 28(2), 617-644.

doi:10.1207/s15326942dn2802_4

Hughes, C., \& Graham, A. (2002). Measuring executive functions in childhood: Problems and solutions?. Child and Adolescent Mental Health, 7(3), 131-142. doi:10.1111/14753588.00024

Isquith, P. K., Crawford, J. S., Espy, K. A., \& Gioia, G. A. (2005). Assessment of executive function in preschool-aged children. Developmental Disabilities Research Reviews, 11(3), 209-215. doi:10.1002/mrdd.20075

Ivrendi, A. (2011). Influence of self-regulation on the development of children's number sense. Early Childhood Education Journal, 39(4), 239-247. doi:10.1007/s10643-011-0462-0

Jacob, R. \& Parkinson, J. (2015). The potential for school-based interventions that target executive function to improve academic achievement: A review. Review of Educational Research, 85(4), 512-552. doi:10.3102/0034654314561338

Kagan, J., Rosman, B. L., Day, D., Albert, J., \& Phillips, W. (1964). Information processing in the child: Significance of analytic and reflective attitudes. Psychological Monographs: General and Applied, 78(1), 1-37. doi:10.1037/h0093830 
Klahr, D. (1978). Goal formation, planning, and learning by preschool problem solvers or: 'My socks are in the dryer'. In R. Siegler (Ed.), Children's thinking: What develops? (pp. 181-211). Hillside, NJ: Erlbaum.

Klahr, D., \& Robinson, M. (1981). Formal assessment of problem solving and planning processes in preschool children. Cognitive Psychology, 13, 113-148. doi:10.1016/00100285(81)90006-2

Klein, A., Starkey, P., \& Wakeley, A. (2000). Child Math Assessment: Preschool Battery (CMA). Berkeley, CA: University of California, Berkeley.

Klingberg, T. (2010). Training and plasticity of working memory. Trends in Cognitive Sciences, 14(7), 317-324. doi:10.1016/j.tics.2010.05.002

Krikorian, R., \& Bartok, J. A. (1998). Developmental data for the Porteus maze test. The Clinical Neuropsychologist, 12(3), 305-310. doi:10.1076/clin.12.3.305.1984

Lemmon, K., \& Moore, C. (2007). The development of prudence in the face of varying future rewards. Developmental Science, 10, 502-511. doi:10.1111/j.1467- 7687.2007.00603.x

Mazzocco, M. M. M., \& Kover, S. T. (2007). A longitudinal assessment of executive function skills and their association with math performance. Child Neuropsychology, 13(1), 1845. doi:10.1080/09297040600611346

McClelland, M. M., \& Cameron, C. E. (2012). Self-regulation in early childhood: Improving conceptual clarity and developing ecologically valid measures. Child Development Perspectives, 6(2), 136-142. doi:10.1111/j.1750-8606.2011.00191.x

McClelland, M. M., Cameron, C. E., Connor, C. M., Farris, C. L., Jewkes, A. M., \& Morrison, F. J. (2007). Links between behavioral regulation and preschoolers' literacy, vocabulary, and math skills. Developmental Psychology, 43(4), 947-959. doi:10.1037/0012- 
1649.43.4.947

McClelland, M. M., Cameron, C. E., Duncan, R., Bowles, R. P., Acock, A. C., Miao, A., \& Pratt, M. E. (2014). Predictors of early growth in academic achievement: The head-toes-kneesshoulders task. Frontiers in Psychology, 5(599), 1-14. doi:10.3389/fpsyg.2014.00599

Milburn, T. F., Lonigan, C. J., DeFlorio, L, \& Klein, A. (2019). Dimensionality of preschoolers' informal mathematical abilities, Early Childhood Research Quarterly, 47, 487-495. doi:10.1016/j.ecresq.2018.07.006

Miller, H. V., Barnes, J. C., \& Beaver, K. M. (2011). Self-control and health outcomes in a nationally representative sample. American Journal of Health Behavior, 35, 15- 27. doi:10.5993/AJHB.35.1.2

Miller, P., \& Votruba-Drzal, E. (2013). Early academic skills and childhood experiences across the urban-rural continuum. Early Childhood Research Quarterly, 28(2), 234-248. doi:10.1016/j.ecresq.2012.12.005

Miller, P., Votruba-Drzal, E., \& Setodji, C. M. (2013). Family income and early achievement across the urban-rural continuum. Developmental Psychology, 49(8), 1452-1465. doi: $10.1037 / \mathrm{a} 0030244$

Morgan, P. L., Farkas, G., Wang, Y., Hillemeier, M. M., Oh, Y. \& Maczuga, S. (2019). Executive function deficits in kindergarten predict repeated academic difficulties across elementary school. Early Childhood Research Quarterly, 46, 20-32. doi: 10.1016/j.ecresq.2018.06.009

Mulder, H., Verhagen, J., Van der Ven, S. H. G., Slot, P. L., \& Leseman, P. P. M. (2017) Early executive Function at age two predicts emergent mathematics and literacy at age five, Frontiers in psychology, 8: 1706, doi:10.3389/fpsyg.2017.0176. 
Müller, U., Dick, A. S., Gela, K., Overton, W. F., \& Zelazo, P. D. (2006). The role of negative priming in preschoolers' flexible rule use on the dimensional change card sort task. Child Development, 77(2), 395-412. doi:10.1111/j.1467- 8624.2006.00878.x

Nesbitt, K. T., Fuhs, M. W., \& Farran, D. C. (2019). Stability and instability in the codevelopment of mathematics, executive function skills, and visual-motor integration from prekindergarten to first grade. Early Childhood Research Quarterly, 46, 262-274. doi:10.1016/j.ecresq.2018.02.003

Nguyen, T. \& Duncan,G. J. (2019). Kindergarten components of executive function and third grade achievement: A national study. Early Childhood Research Quarterly, 46, 49-61. doi:10.1016/j.ecresq.2018.05.006

O’Hare, W. P., Mather, M., Dupuis, G., Land, K. C., Lamb, V. L., \& Fu, Q. (2013). Analyzing differences in child well-being among U.S. states. Child Indicators Research, 6(2). 401431. doi:10.1007/s12187-012-9173-3

Oberer, N., Gashaj, V., \& Roebers, C. M. (2018). Executive functions, visual-motor coordination, physical fitness and academic achievement: Longitudinal relations in typically developing children. Human Movement Science, 58, 69-79. doi:10.1016/j.humov.2018.01.003

Ponitz, C. C., McClelland, M. M., Matthews, J. S., \& Morrison, F. J. (2009). A structured observation of behavioral self-regulation and its contribution to kindergarten outcomes. Developmental Psychology, 45(3), 605-619. doi:10.1037/a0015365

Porteus, S. D. (1965). Porteus maze tests: Fifty years' application. Palo Alto, CA: Pacific Books. Provasnik, S., KewalRamani, A., Coleman, M.M., Gilbertson, L., Herring, W., and Xie, Q. (2007). Status of Education in Rural America (NCES 2007-040). National Center for 
Education Statistics, Institute of Education Sciences, U.S. Department of Education. Washington, DC. Retrieved from https://nces.ed.gov/pubsearch/pubsinfo.asp?pubid=2007040

Purpura, D. J., Schmitt, S. A., \& Ganley, C. M. (2017). Foundations of mathematics and literacy: The role of executive functioning components. Journal of Experimental Child Psychology, 153, 15-34. doi:10.1016/j.jecp.2016.08.010

Raver, C. C., \& Blair, C. (2016). Neuroscientific Insights: Attention, Working Memory, and Inhibitory Control. The Future of Children, 26(2), 95-118. doi:10.1353/foc.2016.0014

Rhoads, C. L., Miller, P. H., \& Jaeger, G. O. (2018). Put your hands up! Gesturing improves preschoolers' executive function. Journal of Experimental Child Psychology, 173, 41-58. doi:10.1016/j.jecp.2018.03.010

Robinson, J. P. \& Lubienski, S. T. (2011). The development of gender achievement gaps in mathematics and reading during elementary and middle school: Examining direct cognitive assessments and teacher ratings. American Educational Research Journal, 48(2), 268-302. doi:10.3102/0002831210372249

Rushworth, M. F. S., Passingham, R. E., \& Nobre, A. C. (2005). Components of attentional setswitching. Experimental Psychology, 52, 83-98. doi:10.1027/1618-3169.52.2.83

Schmitt, S. A., Geldhof, G. J., Purpura, D. J., Duncan, R., \& McClelland, M. M. (2017). Examining the relations between executive function, math, and literacy during the transition to kindergarten: A multi-analytic approach. Journal of Educational Psychology, 109(8), 1120-1140. doi:10.1037/edu0000193

Simanowski, S. \& Krajewski (2019). Specific preschool executive functions predict unique aspects of mathematics development: A 3-year longitudinal study, Child Development, 
90, 544-561. doi:10.1111/cdev.12909

Simon, H. A. (1975). The functional equivalence of problem solving skills. Cognitive Psychology, 7(2), 268-288. doi:10.1016/0010-0285(75)90012-2

Snyder, H. R., Kaiser, R. H., Warren, S. L., \& Heller, W. (2015). Obsessive-compulsive disorder is associated with broad impairments in executive function: A meta- analysis. Clinical Psychological Science, 3(2), 301-330. doi:10.1177/2167702614534210

Spreen, O., \& Strauss, E. (1998). A compendium of neuropsychological tests, $\left(2^{\text {nd }} e d.\right)$. New York, NY: Oxford University Press.

St. John, A. M., Kibbe, M., \& Tarullo, A. R. (2019). A systematic assessment of socioeconomic status and executive functioning in early childhood. Journal of Experimental Child Psychology, 178, 352-368. doi:10.1016/j.jecp.2018.09.003

Tudge, J. R., Mokrova, I., Hatfield, B. E., \& Karnik, R. B. (2009). Uses and misuses of Bronfenbrenner's bioecological theory of human development. Journal of Family Theory \& Review, 1, 198-210. doi:10.1111/j.1756-2589.2009.00026.x

Tuvblad, C., May, M., Jackson, N., Raine, A., \& Baker, L. A. (2017). Heritability and longitudinal stability of planning and behavioral disinhibition based on the Porteus Maze Test. Behavior Genetics, 47(2), 164-174. doi:10.1007/s10519-016- 9827-x

United States Department of Agriculture (USDA) (2013). Rural-urban continuum codes. Retrieved from https://www.ers.usda.gov/data-products/rural-urban- continuum-codes/ Wechsler, D. (2002). Wechsler Preschool and Primary Scale of Intelligence (3 ${ }^{\text {rd }}$ ed.). San Antonio, TX: Pearson.

Welsh, M. C., Pennington, B.F., \& Groisser, D.B. (1991). A normative-developmental study of executive function: A window on prefrontal function in children. Developmental 
Neuropsychology, 7, 131-149. doi:10.1080/87565649109540483

Wiebe, S. A., Espy, K. A., \& Charak, D. (2008). Using confirmatory factor analysis to understand executive control in preschool children: I. Latent structure. Developmental Psychology, 44(2), 575-587. doi:10.1037/0012-1649.44.2.575

Wiebe, S. A., Sheffield, T. D., \& Espy, K. A. (2012). Separating the fish from the sharks: A longitudinal study of preschool response inhibition. Child Development, 83(4), 1245-1261. doi:10.1111/j.1467-8624.2012.01765.x

Wolf, S. \& McCoy, D. C. (2019). Household socioeconomic status and parental investments: Direct and indirect relations with school readiness in Ghana. Child Development, 90(1), 260-278. doi:10.1111/cdev.12899

Woodcock, R. W., McGrew, K. S., \& Mather, N. (2001). Woodcock-Johnson III Tests of Cognitive Abilities. Itasca, IL: Riverside.

Zelazo, P. D. (2006). The Dimensional Change Card Sort: A method of assessing executive function in children. Nature Protocols, 1, 297-301. doi:10.1038/nprot.2006.46

Zelazo, P. D., Anderson, J. E., Richler, J., Wallner-Allen, K., Beaumont, J. L., \& Weintraub, S. (2013). II. NIH Toolbox Cognition Battery (CB): Measuring executive function and attention. Monographs of the Society for Research in Child Development, 78(4), 16-33. doi:10.1111/mono.12032 